\title{
Are Meteorological Parameters a Risk Factor for Pulmonary Embolism? A Retrospective Analysis of 530 Patients
}

\author{
Ceyda Anar, Tuba İnal, Serhat Erol, Gülru Polat, İpek Ünsal, Özlem Ediboğlu, Hüseyin Halilçolar \\ Department of Chest Diseases, İzmir Dr. Suat Seren Chest Diseases and Surgery Training and Research Hospital, İzmir, Turkey
}

Background: The influence of meteorological conditions on cardiovascular morbidity and mortality has been known for a long time. However, few reports have been published on the influence of meteorological parameters on the occurrence of acute pulmonary embolism (PE).

Aims: In this retrospective study, we compared the meteorological parameters between PE patients with risk factors and idiopathic PE patients.

Study Design: Cross-sectional study.

Methods: Medical documentation of 1180 patients with suspected acute pulmonary embolism diagnosed between January 2010 and December 2012 was retrospectively analyzed. A total of 530 patients with $\mathrm{PE}$ confirmed by computed tomography pulmonary angiography and/or ventilation/perfusion scan were included for further analysis. We divided the patients into two groups: PE with risk factors (provoked) and PE without risk factors (unprovoked). The meteorological data were collected from the relevant time period: temperature, humidity, pressure, and wind velocity. As the exact time of PE onset was unknown, the meteorological values attributed to each patient were the means of the values in the months or weeks at the time of diagnosis of PE.
Results: The highest numbers of cases were seen in autumn (29.8\%), followed by summer (28.9\%), spring $(22.1 \%)$, and winter (19.2\%). In terms of months, the greatest number of cases occurred in June (57), followed by November (56) and October (54). Case distribution according to the months and seasons were statistically significant. The wind direction also affected the incidence of PE. There was a statistically significant positive correlation between case frequency and air temperature $(r=0.300 ; p=0.031)$. No correlation was found between the unprovoked PE cases' monthly distribution and pressure, humidity, or temperature. However, there was a statistically significant positive correlation between the monthly distribution of the group with provoked $\mathrm{PE}$ cases and air temperature $(\mathrm{r}=0.586$; $\mathrm{p}=0.045$ ).

Conclusion: A statistically significant inverse correlation between atmospheric pressure and temperature and the number of all PE cases was observed in our study, which is in accordance with other reports. However, in unprovoked PE cases, there was no correlation between meteorological parameters and case incidence.

Keywords: Meteorological factors, pulmonary embolism, risk factors 
The influence of meteorological conditions on cardiovascular morbidity and mortality has been known for a long time. However, few reports have been published on the influence of meteorological parameters on the occurrence of acute pulmonary embolism (PE), which is an important public health problem, with high mortality (1). The pathophysiological mechanisms underlying these observations remain controversial. One possible mechanism may be that changes in meteorological factors that occur during the year have a direct effect on thrombotic tendencies. However, studies that have investigated the relationship between meteorological factors and the incidence of PE have provided inconsistent results (2-5). These studies included patients who had risk factors for PE, and therefore, confounding factors may have influenced the results. Although risk factors for PE, such as surgery, cancer, and immobility, may not be directly implicated in terms of the effect of meteorological factors, they could be influenced indirectly (5). We therefore undertook a large study of patients without risk factors for PE. In this retrospective study, we compared the meteorological parameters between the patients who had risk factors (provoked) and idiopathic (unprovoked) PE patients. We looked for seasonal variations in the incidence of idiopathic PE and a relationship with atmospheric pressure, humidity, or temperature.

\section{MATERIALS AND METHODS}

\section{Patients}

Medical documentation of 1180 patients with suspected acute pulmonary embolism diagnosed between January 2010 and December 2012 was retrospectively analyzed. Patients with PE confirmed by computerized tomography pulmonary angiography (CTPA) and ventilation/perfusion (V/Q) scanning were included for further analysis. We divided the patients into two groups: PE with risk factors and PE without risk factors. Patients with a known major risk factor for PE (surgical patients, obstetric patients, trauma/orthopedic patients, and oncology patients) were recorded as group 1 (provoked). As immobility and hospitalization is also a risk factor for PE, patients who were in the hospital for more than 5 days before they had a CTPA or V/Q scan were also included in group 1. Patients who did not have a risk factor were included in group 2 (unprovoked).

This study was approved by the local ethical committee. Informed consent was not obtained from each patient.

\section{Computerized tomography pulmonary angiography}

Computerized tomography pulmonary angiography was obtained using a 64-slice scanner (Imaxeon Salient, Germany) and $80-90 \mathrm{~mL}$ of iodinated contrast material. The same radiologist reported all scans. Patients were investigated by CTPA as their initial investigation or following an intermediate or indeterminate $\mathrm{V} / \mathrm{Q}$ scan.

\section{Ventilation/Perfusion scan}

All scans were reviewed by a radiologist and classified according to the Prospective Investigation of Pulmonary Embolism Diagnosis (PIOPED) criteria. Normal or low probability scans were classified as negative, while those with high probability were classified as positive. Patients with intermediate or indeterminate probability scans were subsequently investigated with CT pulmonary angiography.

\section{Seasons}

For each year, standard dates were used to define each season. Summer was defined as June 1 to August 31, autumn was defined as September 1 to November 30, winter was defined as December 1 to February 28/29 (depending on whether or not it was a leap year), and spring was defined as March 1 to May 31.

\section{Meteorological factors}

The following meteorological data were collected from the relevant time period: temperature, humidity, pressure, and wind velocity. These meteorological data were obtained from the İzmir Meteorology Department. The exact time of PE onset was unknown, and hence the meteorological values attributed to each patient were means of the values in the months or weeks at the time of diagnosis of PE.

\section{Statistical analysis}

Data was analyzed using SPSS 16.0 (SPSS Inc., Chicago, IL, USA) statistical package. Measurement data are expressed as mean $\pm \mathrm{SD}$. The $\chi^{2}$ test was used to compare baseline characteristics and the number of patients presenting in each month and season. A p-value $\leq 0.05$ was regarded as indicating statistical significance. Pearson's correlation was used to determine the correlation between the average atmospheric pressure, humidity, air temperature values, and PE incidence for each month and season.

\section{RESULTS}

The demographic characteristics of the patients are shown in Table 1. Apart from gender, no statistical significance was determined in terms of patient characteristics and risk factors. CTPA was used as the diagnostic tool in 500 patients, whereas 
TABLE 1. Patient characteristics and risk factors according to season

\begin{tabular}{|c|c|c|c|c|c|}
\hline Characteristics & $\begin{array}{l}\text { Winter } \\
n=102\end{array}$ & $\begin{array}{l}\text { Spring } \\
\mathrm{n}=117\end{array}$ & $\begin{array}{c}\text { Summer } \\
n=153\end{array}$ & $\begin{array}{c}\text { Autumn } \\
\mathrm{n}=158\end{array}$ & $\mathrm{p}$ \\
\hline Female/male & $39 / 63$ & $46 / 71$ & $90 / 63$ & $84 / 74$ & 0.001 \\
\hline Immobilization & $7(6.9 \%)$ & $8(6.8 \%)$ & $25(16.3 \%)$ & $14(8.9 \%)$ & 0.065 \\
\hline Trauma & $3(2.9 \%)$ & $12(10.3 \%)$ & $5(3.3 \%)$ & $5(3.2 \%)$ & 0.117 \\
\hline Surgery & $7(6.9 \%)$ & $12(10.3 \%)$ & $18(11.8)$ & $22(13.9 \%)$ & 0.232 \\
\hline Recurrent PE & $6(5.9 \%)$ & $1(0.9 \%)$ & $5(3.3)$ & $2(1.3 \%)$ & 0.065 \\
\hline $\operatorname{DVT}(+/-)$ & $32 / 70$ & $40 / 77$ & $39 / 114$ & $60 / 98$ & 0.121 \\
\hline Obesity & - & - & $2(1.3 \%)$ & - & 0.452 \\
\hline Contraceptive drug use & $3(2.9 \%)$ & $3(2.6)$ & $3(2 \%)$ & $4(2.5 \%)$ & 0.650 \\
\hline Malignancy & $10(9.8 \%)$ & $16(13.7 \%)$ & $19(12.4 \%)$ & $20(13.9 \%)$ & 0.125 \\
\hline Cardiovascular disease & $14(13.7 \%)$ & $23(19.7 \%)$ & $23(15 \%)$ & $21(13.3 \%)$ & 0.114 \\
\hline COPD & $5(4.9 \%)$ & $6(5.1 \%)$ & - & $8(5.1 \%)$ & 0.230 \\
\hline \multirow[t]{2}{*}{ No risk factors } & $46(45.1 \%)$ & $35(29.9 \%)$ & $53(34.6 \%)$ & $61(38.6 \%)$ & 0.115 \\
\hline & \multicolumn{4}{|c|}{ Diagnosis } & \\
\hline CT Angiography & $96(94.1 \%)$ & $112(95.7 \%)$ & $139(90.8 \%)$ & $153(96.8 \%)$ & 0.124 \\
\hline Isotope lung scanning & $6(5.9 \%)$ & $5(4.3 \%)$ & $14(9.2 \%)$ & $5(3.2 \%)$ & 0.124 \\
\hline Mortality (+/-) (present/absent) & $5 / 97$ & $2 / 113$ & $6 / 147$ & $5 / 153$ & 0.680 \\
\hline Massive/non-massive PE & $10 / 92$ & $14 / 103$ & $12 / 141$ & $12 / 146$ & 0.582 \\
\hline
\end{tabular}

PE: pulmonary embolism; DVT: deep venous thrombosis; CT: computerized tomography; COPD: chronic obstructive pulmonary disease

30 patients were diagnosed clinically using isotope lung scanning. Risk factors were shown in 335 (63.2\%) patients, while $195(36.8 \%)$ patients had no risk factors.

The highest numbers of cases were seen in autumn (29.8\%), followed by summer $(28.9 \%)$, spring $(22.1 \%)$, and winter $(19.2 \%)$, and this difference was statistically significant $(\mathrm{p}=0.001$; Figure 1$)$. In terms of months, the greatest number of cases occurred in June (57), followed by November (56) and October (54), and this distribution was also statistically significant ( $\mathrm{p}=0.027$; Figure 2$)$.

The wind direction affected the incidence of $\mathrm{PE}$ and was statistically significant ( $\mathrm{p}=0.000$; Figure 3 ).

There was a statistically significant positive correlation between case frequency and air temperature $(\mathrm{r}=0.300$; $\mathrm{p}=0.031$ ). There was a negative correlation between embolism cases and atmospheric pressure $(\mathrm{r}=-0.263 ; \mathrm{p}=0.060)$ and with humidity $(\mathrm{r}=-0.905 ; \mathrm{p}=0.504)$, although these were not statistically significant (Table 2). There was no statistically significant difference between cases and air temperature, humidity, atmospheric pressure, or wind speed between the group with risk factors and without risk factors (Table 3).

Considering embolism cases occurring with risk factors and without risk factors, it was determined that the distribution ratios by month and season were not statistically significant ( $p=0.281$ and 0.115 , respectıvely; Figure 4, Table 4). However, there was a statistically significant positive correlation between the monthly distribution of cases from the group with

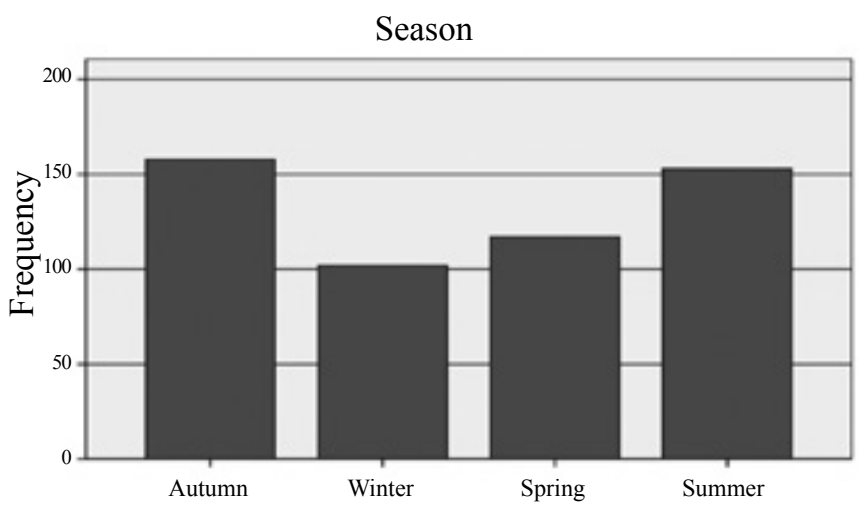

FIG. 1. The number of patients according to the season

risk factors and air temperature ( $\mathrm{r}=0.586 ; \mathrm{p}=0.045$; Figure 5). Although not statistically significant, there was a negative correlation between PE cases with risk factors and humidity $(\mathrm{r}=-0.510 ; \mathrm{p}=0.09)$ and atmospheric pressure $(\mathrm{r}=-0.538$; $\mathrm{p}=0.071$; Table 3).

\section{DISCUSSION}

The first observation of the weather's influence on health is attributed to Hippocrates (7). The effect of the weather and the seasons on cardiovascular and cerebrovascular diseases had been investigated for many years. Goerre et al. (8) analyzed 


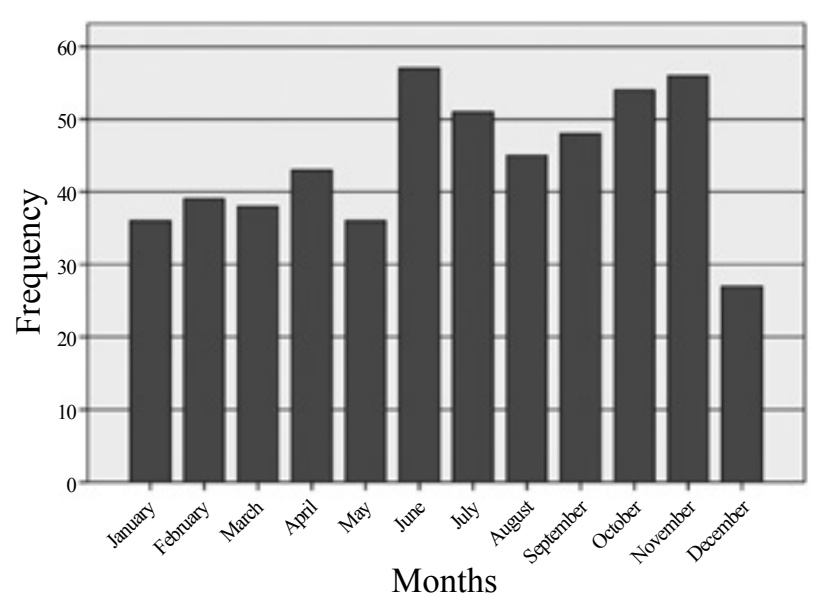

FIG. 2. The number of patients according to the month

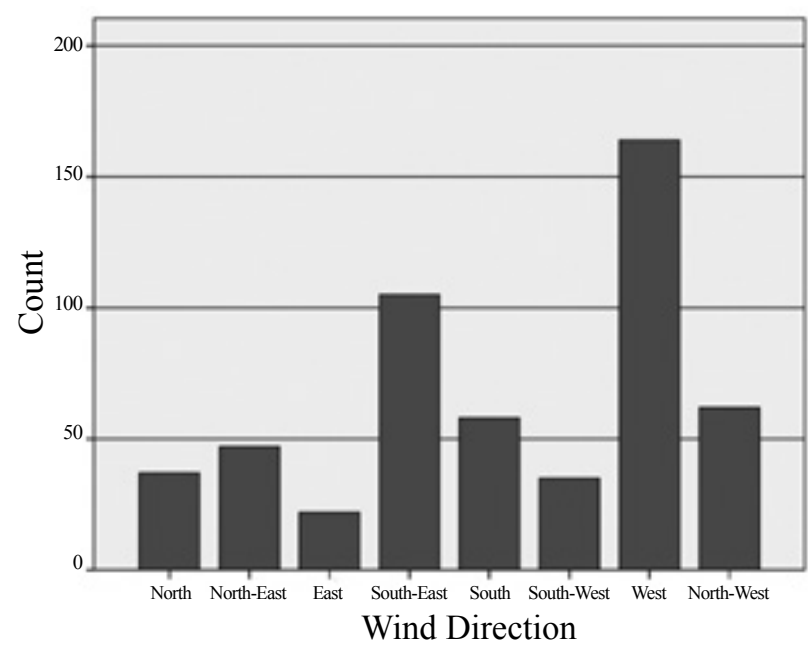

FIG. 3. The distribution of patients according to the wind direction

TABLE 2. Correlation between all pulmonary embolism cases and meteorological parameters (weekly and monthly)

\begin{tabular}{lccc}
\hline & & $\begin{array}{c}\text { PE frequency } \\
\text { weekly }\end{array}$ & $\begin{array}{c}\text { PE frequency } \\
\text { monthly }\end{array}$ \\
\hline Wind speed & $\mathrm{r}^{*}$ & 0.141 & 0.31 \\
Temperature & $\mathrm{p}$ & 0.318 & 0.32 \\
Humidity & $\mathrm{r}$ & $0.300^{*}$ & $0.572^{*}$ \\
Atmospheric pressure & $\mathrm{p}$ & 0.03 & 0.05 \\
& $\mathrm{r}$ & -0.095 & -0.473 \\
& $\mathrm{p}$ & 0.5 & 0.121 \\
& $\mathrm{p}$ & -0.263 & -0.423 \\
\hline
\end{tabular}

r: correlation coefficient; $p$ : p value; PE: pulmonary embolism

the impact of weather conditions on the incidence of acute coronary syndrome (ACS). Their study, which included 6560 patients hospitalized due to myocardial infarction, revealed that high ambient pressure, high pressure gradients,
TABLE 3. The distribution of meteorological parameters between the cases with risk factors and without risk factors

\begin{tabular}{lccc}
\hline & PE cases with & $\begin{array}{c}\text { PE cases without } \\
\text { risk factors }\end{array}$ \\
\hline Wind speed & $\mathrm{r}^{*}$ & 0.365 & -0.287 \\
(monthly) & $\mathrm{p}$ & 0.243 & 0.366 \\
Temperature & $\mathrm{r}$ & 0.586 & 0.358 \\
(monthly) & $\mathrm{p}$ & 0.045 & 0.254 \\
Humidity & $\mathrm{r}$ & -0.510 & -0.072 \\
& $\mathrm{p}$ & 0.09 & 0.823 \\
Atmospheric pressure & $\mathrm{r}$ & -0.538 & -0.235 \\
& $\mathrm{p}$ & 0.071 & 0.462 \\
\hline
\end{tabular}

PE: pulmonary embolism; r: correlation coefficient; $p$ : $p$ value

Month

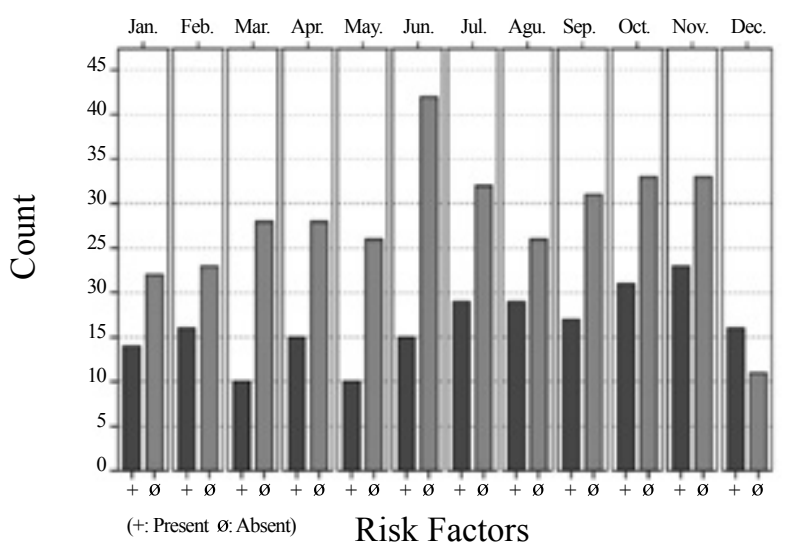

FIG. 4. Patients with risk factors and without risk factors according to the month

and strong wind activity are associated with an increase in ACS cases. Dawson et al. (9) analyzed changes in weather conditions and compared them with hospital admissions due to cerebrovascular incidents.

There is no consensus among researchers on the seasonality of PE occurrence. Masotti et al. (10) revealed an increased occurrence of PE in surgical patients during cold months, as well as during longer periods of hospitalization of those patients in the same season. The same study showed an increased number of PE incidents during warm months in the cardiology ward. Similar to Nimako et al. (11), our study showed a correlation between the incidence of PE (idiopathic and with risk factors) and decreased atmospheric pressure and increased temperature. However, no correlation was determined between monthly distribution in the group without risk factors and pressure, humidity, or temperature. There was no statistically significant difference between case characteristics and air temperature, humidity, atmospheric pressure, or wind speed between the group with risk factors and without risk factors in our study population. Oztuna et 
TABLE 4. The distribution of patients in two groups

\begin{tabular}{|c|c|c|c|}
\hline & $\begin{array}{l}\text { Without risk } \\
\text { factors }\end{array}$ & $\begin{array}{l}\text { With risk } \\
\text { factors }\end{array}$ & $\mathrm{p}$ \\
\hline Female/Male & $74 / 121$ & $185 / 150$ & 0.000 \\
\hline DVT (-/+) & $123 / 72$ & $236 / 99$ & 0.08 \\
\hline & Seasons & & \multirow{5}{*}{0.115} \\
\hline Autumn & 61 & 97 & \\
\hline Winter & 46 & 56 & \\
\hline Spring & 35 & 82 & \\
\hline Summer & 53 & 100 & \\
\hline \multicolumn{4}{|c|}{ Months } \\
\hline January & 14 & 22 & \multirow{12}{*}{0.281} \\
\hline February & 16 & 23 & \\
\hline March & 10 & 28 & \\
\hline April & 15 & 28 & \\
\hline May & 10 & 26 & \\
\hline June & 15 & 42 & \\
\hline July & 19 & 32 & \\
\hline August & 19 & 26 & \\
\hline September & 17 & 31 & \\
\hline October & 21 & 33 & \\
\hline November & 23 & 33 & \\
\hline December & 16 & 11 & \\
\hline \multicolumn{4}{|c|}{ Years } \\
\hline 2010 & 56 & 50 & \multirow{3}{*}{0.000} \\
\hline 2011 & 58 & 166 & \\
\hline 2012 & 81 & 119 & \\
\hline \multicolumn{4}{|c|}{ Mortality } \\
\hline Abcent & 189 & 321 & \multirow{2}{*}{0.685} \\
\hline Present & 6 & 14 & \\
\hline \multicolumn{4}{|c|}{ Diagnosis test } \\
\hline CT Angiography & 179 & 321 & \multirow{2}{*}{0.082} \\
\hline V/P Scintigraphy (V/P scan) & 16 & 14 & \\
\hline \multicolumn{4}{|c|}{ Severity } \\
\hline Massive & 17 & 31 & \multirow{2}{*}{0.96} \\
\hline Non-massive & 178 & 304 & \\
\hline
\end{tabular}

al. (3) found an insignificant negative correlation between the monthly distribution in cases without risk factors and air pressure and humidity in their study, but no correlation was determined in medical cases. In contrast, Masotti's (10) 457 case study reported that although a powerful correlation with atmospheric pressure was found in surgical cases, there was only a weak correlation between air pressure, humidity, and temperature in medical cases.

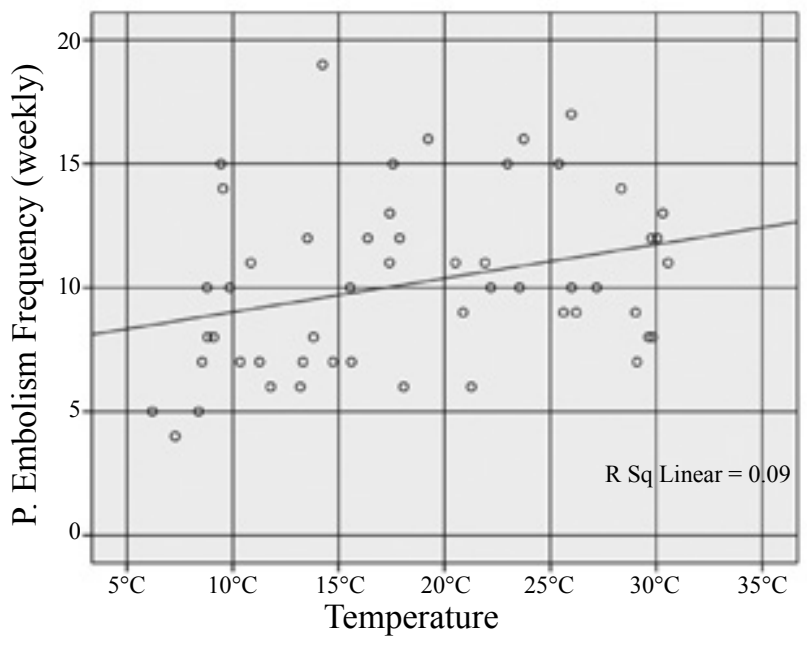

FIG. 5. Correlation between pulmonary embolism patients with risk factors and temperature

Our findings of a seasonal variation in PE are consistent with a number of similar studies. Most of these have found an increased incidence of PE or venous thromboembolism in the autumn and winter months (12-15). Consistent with our findings, Manfredini et al. (15), in a large multicenter Italian study (2119 subjects), found that venous thromboembolisms were less frequent in spring. However, in contrast to our findings, Meral et al. (2) found a peak in the incidence of PE in the spring months. However, this was a small study (91 patients) that took place at high altitude $(1800 \mathrm{~m})$, with very different weather conditions to our own. These different results may be due to climatic differences in the study centers and their geographical structures. However, it is also true that people are more likely to travel in cars for longer distances on hotter days and during the holiday period. Dehydration is more likely to be a problem in the hotter months due to perspiration, and this may lead to an increase in blood viscosity and PE. Also, a further limitation of our study is that although our hospital is far from the weather station (approximately $15 \mathrm{~km}$ ), it is conceivable that some patients may have lived a lot farther than $15 \mathrm{~km}$ from the weather station. Consequently, the meteorological factors that they were exposed to would have been different from that recorded at the weather station. However, there was no difference between the PE cases with risk factors and those without risk factors in our study, and there was also no correlation between incidence of PE with atmospheric pressure, temperature, or humidity in idiopathic PE.

The highest mortality in a 2831-case series studied by Montes et al. (16) from 1996 to 2001 occurred in the spring months (OR, 2.18; CI, 1.18-4.05), and $83 \%$ of the patients who died were older than 75 years. Oztuna et al. (3) found that the highest mortality in their study was also in winter and spring, although this was not statistically significant. In our 
study, the highest mortality was in autumn. The average age of the 20 patients who died was $68.63 \pm 18.42$ years, which is in contrast to the Montes et al. (16) study. In Montes et al. (16) study mortality peaked in spring and nearly $83 \%$ of these deaths occurred in persons $>75$ years old. Also, in our study massive embolism had occurred in 11 patients and nine patients had non-massive embolism, which was statistically significant in our study.

In conclusion, a statistically significant inverse correlation between atmospheric pressure and temperature and the number of all PE cases was observed in our study, which is in accordance with other reports. This result raises a question: We know that long commercial flights are a risk factor for PE. Can cabin pressure changes and humidity be responsible for PE and deep-vein thrombosis during flights? If the answer is yes, then, commercial aircraft manufacturers have a big problem. Of course, we need further perspective and wellorganized studies to answer this question.

Ethics Committee Approval: Ethics committee approval was received for this study from the ethics committee of İzmir Dr. Suat Seren Chest Diseases and Surgery Training Research Hospital.

\section{Informed Consent: N/A.}

Peer-review: Externally peer-reviewed.

Author contributions: Concept - C.A., İ.Ü., S.E.; Design - C.A., İ.Ü., T.İ.; Supervision - C.A., İ.Ü., H.H.; Resource - C.A., G.P., Ö.E.; Materials - C.A., T.İ., Ö.E.; Data Collection \&/or Processing - C.A., T.I., S.E.; Analysis \&/or Interpretation - C.A., S.E., G.P.; Literature Search - C.A., İ.Ü., Ö.E.; Writing - C.A., S.E., G.P.; Critical Reviews - İ.Ü., H.H., Ö.E.

Acknowledgements: The authors would like to thank the İzmir Meterological Service for providing the meteorological data.

Conflict of Interest: No conflict of interest was declared by the authors.

Financial Disclosure: The authors declared that this study has received no financial support.

\section{REFERENCES}

1. Stein PD, Kayali F, Olson RE. Analysis of occurrence of venous thromboembolic disease in the four seasons. Am J Cardiol 2004;93:511-3. [CrossRef]
2. Meral M, Mirici A, Aslan S, Akgun M, Kaynar H, Saglam $\mathrm{L}$, et al. Barometric pressure and the incidence of pulmonary embolism. Chest 2005;128:2190-4. [CrossRef]

3. Oztuna F, Ozsu S, Topbas M, Bülbül Y, Koşucu P, Ozlü T. Meteorological parameters and seasonal variations in pulmonary thromboembolism. Am J Emerg Med 2008;26:103541. [CrossRef]

4. Scott JA, Palmer EL, Fischman AJ, Strauss HW. Meteorologic influences on the frequency of pulmonary embolism. Invest Radiol 1992;27:583-6. [CrossRef]

5. Clauss R, Mayes J, Hilton P, Lawrenson R. The influence of weather and environment on pulmonary embolism: pollutants and fossil fuels. Med Hypotheses 2005;64:1198-201. [CrossRef]

6. The PIOPED Investigators. Value of the ventilation/perfusion scan in acute pulmonary embolism. Results of the prospective investigation of pulmonary embolism diagnosis (PIOPED). JAMA 1990;263:2753-9. [CrossRef]

7. Kevan SM. Quests for cures: a history of tourism for climate and health. Int J Biometeorol 1993;37:113-24. [CrossRef]

8. Goerre S, Egli C, Gerber S, Defila C, Minder C, Richner H, et al. Impact of weather and climate on the incidence of acute coronary syndromes. Int J Cardiol 2007;118:36-40. [CrossRef]

9. Dawson J, Weir C, Wright F, Bryden C, Aslanyan S, Lees K, et al. Associations between meteorological variables and acute stroke hospital admissions in the west of Scotland. Acta Neurol Scand 2007;117:85-9. [CrossRef]

10. Masotti L, Ceccarelli E, Forconi S, Cappelli R. Seasonal variation of pulmonary embolism in hospitalized patients. Respir Med 2005;99:1469-73. [CrossRef]

11. Nimako K, Poloniecki J, Draper A, Rahman T. Seasonal variability and meteorological factors: retrospective study of the incidence of pulmonary embolism from a large United Kingdom teaching hospital. Respir Care 2012;57:1267-72. [CrossRef]

12. Boulay F, Berthier F, Schoukroun G, Raybaut C, Gendreike Y, Blaive B. Seasonal variations in hospital admission for deep vein thrombosis and pulmonary embolism: analysis of discharge data. BMJ 2001;323:601-2. [CrossRef]

13. Sharma GV, Frisbie JH, Tow DE, Yalla SV, Khuri SF. Circadian and circannual rhythm of nonfatal pulmonary embolism. Am J Cardiol 2001;87:922-4. [CrossRef]

14. Manfredini R, Gallerani M, Boari B, Salmi R, Mehta RH. Seasonal variation in onset of pulmonary embolism is independent of patients' underlying risk comorbid conditions. Clin Appl Thromb Hemost 2004;10:39-43. [CrossRef]

15. Manfredini R, Imberti D, Gallerani M, Verso M, Pistelli R, Ageno W, et al. Seasonal variation in the occurrence of venous thromboembolism: data from the MASTER Registry. Clin Appl Thromb Hemost 2009;15:309-15. [CrossRef]

16. Montes Santiago J, Rey Garcia G, Mediero Dominguez A. Seasonal variations in morbidity and mortality for pulmonary embolism in Galicia, Spain. An Med Interna 2003;20:457-60. 